\title{
Sistema de Tecnologia de Grupo: Um Estudo de Caso Através de Análise do Fluxo da Produção
}

\author{
Newton Ribeiro dos Santos, (D.Sc.) \\ Professor do Centro Federal de Educação Tecnológica de Minas Gerais \\ Av. Amazonas, 7675 - 30.510.00, B. Horizonte, MG \\ E-mail:newton@dppg.cefetmg.br \\ Lindolpho Oliveira de Araújo Junior, (M.Tc.) \\ Professor do Centro Federal de Educação Tecnológica do Paraná \\ Rodovia PR-469, Km 01 cep 85.503-390, Pato Branco, PR \\ E-mail:lindolph@cefet.whiteduck.com.br
}

\section{Resumo}

Propōe-se uma implementaçāo computacional da análise do fluxo da produçāo para uma empresa de pequeno porte, isto ć, o "software" GROUPTEC. Através do GROUPTEC elaborou-se um estudo de caso, relativo a uma empresa Paranaense do ramo de produtos manufaturados em alumínio. Realizaram-se quatro análises que compōem a análise do fluxo da produçăo, a saber, análise do fluxo da fábrica, análise de grupo, análise de linha e análise do ferramental. Após a aplicação desta técnica, chegaram-se aos resultados finais quanto às células tecnológicas e seus elementos constituintes, as famílias de peças e os grupos de máquinas, em um arranjo celular otimizado, com uma eficiência de agrupamento de aproximadamente $98 \%$. Estimou-se um ganho de produtividade de $30 \%$ do tempo de movimento das peças c o de filas de espera ao pé-da-máquina.

Abstract

In this work, a computational implementation of the production flow analysis for a small company, namelly, the software GROUPTEC, has been proposed. Using GROUPTEC a case study has been divised and applied to a "Paranaense" company from the branch of aluminum manufactured products. Four analyses of the production flow analysis have been performed, that is, the factory flow analysis, group analysis, line analysis and tool analysis. After the application of the above technique, the final results related to the technological cells and their constituent elements, part families and machinery groups lead to an optimized cell arrangement, with a grouping efficiency of approximately $98 \%$. A productivity gain of $30 \%$ has been estimated with the time-inmovement of the parts and time-in-waiting-lines at the machine.

Palavras Chaves:

Manufatura, CIM, Tecnologia, Grupo, Celular.

Key words:

Manufacturing, Technology, Group, Cellular

\section{Introdução}

É notório que a globalização da economia tem levado muitos países a uma corrida contra o tempo, na intenção de vencer o desafio da necessidade de modificar significativamente o quadro mundial de produção de bens de consumo, sob pena de perder a disputa pela hegemonia do mercado. Cada vez mais, técnicas avançadas vêm sendo desenvolvidas, com o intuito de otimizar a produção com garantia da qualidade, a menores custos, com alta flexibilidade, alta produtividade, produção em pequenos lotes, o que se torna uma tendência mundial. Muitas ferramentas foram desenvolvidas para esse fim, sendo algumas mais ou menos eficazes que as outras.

Cerca de $75 \%$ das peças produzidas nas indústrias metalúrgicas o são em lotes menores que 50 peças, sendo que existe a tendência de aumentar a diversificação de peças e produtos 
PRODUÇÃO

aumentando a necessidade de novas técnicas de planejamento da produção. Constata-se, em alguns casos, que cerca de $95 \%$ do tempo gasto para produzir uma peça resulta de movimento de material pela fábrica e espera ao pé-da-máquina; além disso, o conjunto de peças é desordenado e o planejamento de processos se torna uma tarefa muito difícil e geralmente longas filas são formadas, durante o processo produtivo, devido a gargalos.

Contudo, o aumento da produtividade pode ser conseguido com a redução do fluxo de informações necessárias para o projeto e reorganizando o setor produtivo. Para isso se utiliza a tecnologia de grupo (TG).

Sabe-se que a TG pode ser vista como fator significativo para a integração total de uma indústria no sentido de que proporciona uma organização básica de todos os componentes a serem produzidos pela fábrica, através da classificação e codificação destes em características similares. As técnicas de classificação e codificação são empregadas de acordo com as características do problema a ser tratado, possibilitando que informações relativas ao projeto, processos de fabricação e insumos, em geral, possam ser armazenados através de códigos e recuperados a qualquer tempo conforme a necessidade. Um fator bastante relevante neste caso é o fato da classificação e, portanto, também a codificação poderem ser feitas de maneira natural, ou seja, utilizando os próprios códigos da empresa com gerenciamento através do "software". A flexibilização do sistema permite que informações pertinentes aos planos de processos possam ser usadas na reorganização dos processos produtivos com a intenção de otimizar o chão de fábrica. Muitos autores pesquisaram algoritmos capazes de tais feitos e destacaram suas vantagens, porém não explicitaram quais seriam as conseqüências inde- sejáveis da má utilização de tais técnicas por não trabalharem com estes elementos em suas análises. Há pouca literatura, portanto, relatando pesquisas sobre avaliação de tais algoritmos explorando suas vantagens, desvantagens e como medir sua eficiência.

O estudo das características das máquinas, peças, operações, ferramentas e do tipo de produção utilizada possibilita a identificação da classe de problema que está sendo tratado e das melhores técnicas de TG para resolvê-lo.

Segundo Souza (1991) a concepção de um sistema de produção celular para o tipo de problema a ser tratado por TG requer a utilização da técnica de análise do fluxo da produção (AFP), face à necessidade da substituição do sistema de produção existente (em funcionamento) por outro de produção celular. Em Choi (1996) é apresentado um estudo exploratório de variáveis que afetam a conversão de sistemas para um "layout" celular. $\mathrm{O}$ autor diz que o sucesso de uma conversão para um sistema celular requer um bom manuseio das variáveis e um completo entendimento de como estas variáveis se interagem e as possíveis relações entre elas. Como essas variáveis podem afetar os resultados da conversão para um sistema celular, ou seja, tornando o chãode-fábrica otimizado, também são mostrados pelo autor. Afirma, ainda, que as variáveis como variedade de produtos e volume de produção podem ser aumentadas, assim como, as variáveis custos de produção e tempo de produção podem ser diminuídas. As'variáveis apresentadas pelo autor dizem respeito a indústrias metalúrgicas com processos de usinagem apenas.

Em Crama e Oosten (1996), Cheng et al. (1996), Gupta et al. (1996), Boctor (1996) encontram-se modelos para a formação de famílias de peças e grupos de máquinas para "layout" celular. Cheng et al. (1996) apresentam um mode- 
lo para minimizar os movimentos intercelulares utilizando distância como medida. Ủm algoritmo de busca em árvore truncada foi testado por ele em vários problemas obtidos da literatura. $\mathrm{O}$ autor também apresenta uma comparação de seus resultados com os de outros autores.

Apresentam-se, a seguir, alguns conceitos básicos que serão utilizados neste trabalho.

\section{Evolução do conceito CIM e Organização} dos Sistemas Produtivos

A tecnologia de grupo (TG) vem sendo utilizada há cerca de um século pelas indústrias para organização da fábrica, desde Henry Ford até os dias de hoje. No passado eram técnicas esparsas sendo, hoje em dia, um conjunto sistemático de conceitos, aplicado nas indústrias numa escala ampla e abrangente. Muitos conceitos e estratégias foram desenvolvidos após o advento das máquinas automáticas e das máquinas de controle numérico $(\mathrm{CN})$. Seguindo a evolução natural na busca da maior produtividade chegou-se à tecnologia controle numérico computadorizado (CNC). Desenvolveram-se as aplicações de controle adaptativo (CA); criou-se o conceito de centros de usinagem (CDU), de sistemas flexíveis de manufatura (FMS), projeto e fabricação auxiliados por computador (CAD/ CAM), manufatura integrada por computador (CIM) etc.
Neste trabalho, consideram-se os seguintes tipos de "lay-outs" de produção, baseados no arranjo das máquinas, cuja conceituação vem a seguir.

"Layout" em linha de produção: as máquinas são organizadas em seqüência obedecendo às etapas a serem cumpridas para a fabricação do produto, ou seja, cada linha serve a apenas um produto final ou a um conjunto específico de produtos.

"Layout" por organização funcional: todas as máquinas que executam operações semelhantes são colocados dentro de um mesmo departamento. Os produtos, então, caminham através dos departamentos produtivos que são necessários à sua fabricação. Este arranjo é também conhecido como "job shop".

"Layout" Celular: agrupam-se as máquinas de tipos variados, necessárias à produção de uma família de peças. A lista de máquinas utilizadas para executar cada processo é chamada de unidade produtiva (UP) e conjuntos destas vão formar as células.

A manufatura celular é resultado da aplicação da TG a "job-shops", tendo como objetivo a decomposição do sistema produtivo. Esse tipo de produção é também chamado de "cell shop" e aplica-se a sistemas produtivos com médio volume de produção e média variedade de produtos. V. Figura 1.

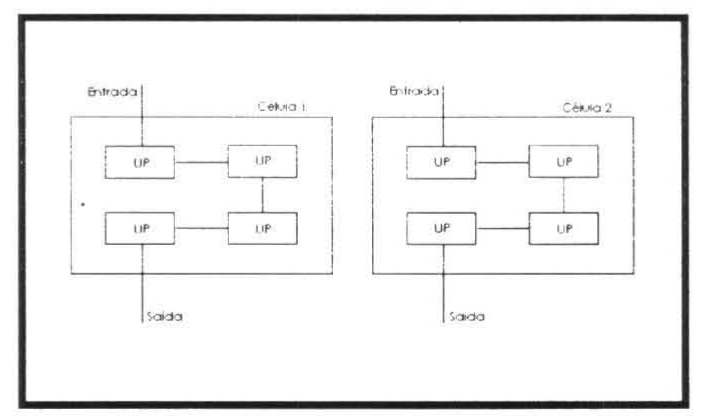

Figura 1 - Organização em Layout Celular. 


\section{PRODUÇÃO}

Os sistemas produtivos são classificáveis conforme o volume de produção e a variedade de produtos a manufaturar. Lacerda (1993) apresenta uma classificação dos sistemas de manufatura, onde o tipo de sistema produtivo é uma relação direta entre o volume de produção por tipo de peça e a variedade de produtos; vide Figura 2.
3. Facilidade de Projeto utilizando TG, Identificação e Tamanho do Problema

Quando as peças são agrupadas em famílias, determinar como arranjar as máquinas na fábrica pode se tornar um grande problema. A reorganização do "layout" existente, seja ele em linha de

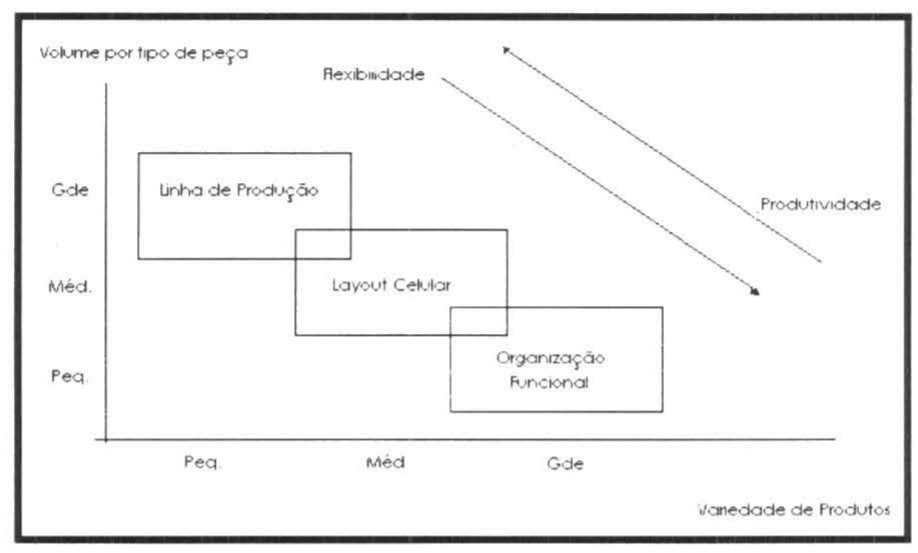

Figura 2 - Classificação dos Sistemas de Manufatura.

Outra característica importante a ser observada é o fato de a flexibilidade e a produtividade se comportarem em relação inversa. Quando se caminha em direção de uma maior flexibilidade, perde-se em produtividade e vice-versa.

Segundo Godoy (1992) a organização celular apresenta pontos de vantagens e desvantagens. De um lado, oferece pontos de motivação caracterizados por redução da movimentação de materiais e produtos, redução dos tempos de preparo das máquinas, redução do tamanho dos lotes de produtos, redução dos estoques intermediários (ao pé da máquina), simplificação do planejamento e controle. De outro lado, os pontos de deficiência podem ocorrer devido à má utilização da TG, sendo caracterizados, principalmente, por maior rigidez do sistema quanto a alterações na produção. transferência ou funcional, é muito importante porque, se as máquinas estão distribuídas de maneira aleatória, os custos de produção podem crescer significativamente.

Num "layout" celular, máquinas são organizadas no chão de fábrica constituindo as células. Cada célula é capaz de processar as operações de manufatura de uma ou mais famílias de peças. Consequentemente, a capacidade de uma célula pode ser determinada considerando apenas as famílias de peças que são aí processadas.

Este tipo de "layout" pode ser facilmente administrado. O procedimento para formação das células é geralmente chamado de agrupamento de máquinas/peças. A análise do fluxo da produção (AFP) é um dos métodos utilizados para esse fim, dentro do escopo da tecnologia de grupo (TG), (Burbidge, 1971). 
No entanto, a AFP requer um certo poder de análise, julgamento e decisão. Como resultado disso, muitas técnicas foram e vem sendo desenvolvidas para auxiliar no agrupamento de máquinas e na formação de famílias de peças.

Retornando à tecnologia de grupo, cumpre lembrar que a mesma constitui uma filosofia de manufatura calcada num conceito básico relativamente simples: identificar e agrupar peças e processos, através de critérios de semelhança, obtendo vantagens ao longo de todos os estágios de projeto e manufatura (Gallacher e Knight, 1986). A definição dos atributos constitui base fundamental para o emprego da TG. Os atributos para agrupamento são baseados em forma geométrica, função e planos de processos para as peças.

As formas geométricas são utilizadas em sistemas CAD, CAM, CAE e CAPP. Nestes sistemas as famílias de peças podem ser formadas conforme características geométricas similares. As funções podem ser utilizadas em sistemas semelhantes para formarem famílias de peças conforme sua função. Já o agrupamento baseado em planos de processos é utilizado para organizar o setor produtivo no sentido de aumentar a produtividade e flexibilidade minimizando os custos associados à produção.
Planos de processos (ou folhas de processos) são documentos contendo todas as informações necessárias à produção de um componente qualquer, ou seja, neles estão contidas todas as informações sobre o componente, desde quando ele entra no setor produtivo ainda como matéria prima até sua transformação em peça acabada.

O desenvolvimento de um módulo de classificação e codificação de atributos para agrupamento em uma base de dados, bem como a criação desta base de dados, é extremamente importante para uma ferramenta de "software" em TG. Os atributos poderão ser especificados de maneira personalizada para cada empresa e dependem do que a empresa produz e dos processos utilizados na produção.

Segundo Kusiak (1990) e Souza (1991) o tamanho do problema em TG depende do número de máquinas e peças processadas pelo setor produtivo e classifica-se de acordo com a Tabela 1. Quanto maior o número de máquinas e peças, mais complexos se tornam a avaliação e a otimização do chão de fábrica.

Para cada tamanho de problema existe a escolha natural dos melhores algoritmos de TG que conduzem à solução e otimização da planta em termos de eficiência de agrupamento, tempos de execução etc.

\begin{tabular}{|c|c|c|}
\hline Tamanho do Problema & $\begin{array}{c}\text { Número de Máquinas } \\
(\mathrm{m})\end{array}$ & $\begin{array}{c}\text { Numero de Peças } \\
(\mathrm{n})\end{array}$ \\
\hline Pequeno & $\mathrm{m}<10$ & $\mathrm{n}<30$ \\
\hline Médio & $10 \leq \mathrm{m}<30$ & $30 \leq \mathrm{n}<60$ \\
\hline Grande & $\mathrm{m} \geq 30$ & $\mathrm{n} \geq 60$ \\
\hline Muito grande & $\mathrm{m}>60$ & $\mathrm{n}>120$ \\
\hline \multicolumn{2}{|c|}{ Tabela 1 - Classificação de problemas na TG. }
\end{tabular}


Cumpre observar que foi escolhido o modelo de TG baseado em planos de processos (PP), descartando-se as abordagens por formas geométricas e função das peças, em razão de a AFP trabalhar com dados relativos aos processos de fabricação visando à otimização da planta. Para a solução de problemas na TG, baseada em PP, são utilizadas três tipos de metodologias: matricial (álgebra linear), programação linear e grafos. Escolheu-se a matricial, neste trabalho, pelo fato de sua implementação computacional ser mais simples.

\section{Análise do Fluxo da Produção (AFP)}

$\mathrm{Na}$ AFP, a preocupação principal é com os métodos de fabricação, não se levando em conta as características de projeto ou a forma dos componentes. Leva-se en consideração o fluxo de materiais pela fábrica e sua manipulação, ou seja, apenas as máquinas e ferramentas que estão realmente em uso.

A AFP depende fundamentalmente de informações procedentes dos planos de processos referentes às peças produzidas; vide Figura 3.
A análise é feita de forma progressiva, através dessas informações, onde divisões naturais em grupos e famílias são obtidas, assim como elementos excepcionais que não se ajustam à solução encontrada para a maioria.

A técnica de análise do fluxo da produção consiste em quatro estágios sucessivos; a saber, análise do fluxo da fábrica (AFF), análise de grupo (AG), análise de linha (AL) e análise do ferramental (AF). Ao contrário de outras técnicas, utilizadas para a geração de tecnologia de grupo, um sistema baseado em AFP requer uma interação maior com o usuário. Os resultados parciais devem ser analisados e decisões devem ser tomadas antes do prosseguimento das etapas subseqüentes, exigindo muito domínio do assunto por parte da pessoa ou equipe que aplica o método. No entanto, este tipo de análise se torna mais fácil devido ao fato de o problema ser atacado por partes evitando a complexidade do tratamento globalizado.

A metodologia de AFP, escolhida em. função das características do problema de TG proposto, requer as seguintes entradas: matriz de incidência de máquinas/peças, número de células, tempo de

\begin{tabular}{|c|c|c|c|c|}
\hline \multicolumn{2}{|c|}{$\begin{array}{l}\text { FOLHA DE PROCESSO } \\
\text { NOME DA PEÇA: } \\
\text { MATERIAL : }\end{array}$} & \multicolumn{3}{|c|}{$\begin{array}{l}\text { NRP: } \\
\text { CÓDIGO: }\end{array}$} \\
\hline Operação & Máquina & Descrição da Operação & Tempo & Departamento \\
\hline & & & & \\
\hline & & & & \\
\hline & & & & \\
\hline
\end{tabular}


operação de cada peça, tempo de máquina e número de máquinas do mesmo tipo. É conveniente lembrar que todas essas informações se encontram nos planos de processos:

Descrevem-se, a seguir, os quatro estágios que compõem a AFP.

\section{a) A análise do fluxo de fábrica}

Esta análise consiste no estudo das rotas ou caminhos pelos quais o material flui pela fábrica. A preocupação maior nesta etapa é com uma divisão em grandes grupos de unidades produtivas e em grandes famílias para cada unidade produtiva, ou seja, importa analisar as rotas sem se preocupar com os processos envolvidos. As etapas para esta análise são: divisão em departamentos, alocação das máquinas por departamento e a determinação da freqüência em uso, determinação do número de rota de processo (NRP), análise de peça por NRP, obtenção da carta de fluxo original, determinação de peças excepcionais, eliminação das exceções, teste de carregamento das máquinas c a especificação de um sistema de fluxo padrão entre departamentos.

\section{b) Análise de Grupo}

Nesta análise, a partir de informações contidas nas folhas de processos, elabora-se, para posterior tratamento computacional, a matriz de incidência de máquinas/peças para cada departamento, dividindo-se as peças em famílias e as máquinas em grupos, de maneira que o processamento de cada família seja obtido em cada grupo.

Denota-se a matriz de incidência $\mathrm{A}$, de ordem $m x p$, onde $m$ corresponde ao número de máquinas da fábrica e $p$, o de peças ou produtos. Seus elementos $a[i, j]$ são constantes binárias contendo o valor 1 , se a máquina i incide no processo de fabricação da peça $\mathrm{j}$, ou o valor 0 , caso contrário.

As etapas para a AG, por sua vez, são as seguintes: enumeração das operações em cada folha de processo, obtenção das famílias de peças e grupos de máquinas (com uso de algoritmo), teste do carregamento e alocação das máquinas, análise das peças excepcionais para eliminação ou reprogramação e, finalmente, a obtenção do fluxo final. Na segunda etapa acima (obtenção de famílias de peças e os grupos de máquinas) obtêm-se as células tecnológicas, através de algoritmos computacionais da álgebra linear, ou seja, diagonalizando-se a matriz de incidência, acima definida, com a aplicação de algoritmos adequados.

Os dados de entrada para os algoritmos estão contidos nas informações tecnológicas, armazenadas anteriormente durante a etapa de cadastramento, tendo como base os planos de processos.

Dentre os algoritmos que tratam a matriz de incidência, selecionou-se o ROC estendido ("Extended Rank Order Clustering Algorithm"), desenvolvido por King, J. R. Nakornchai e citado por Souza (1991).

Este algoritmo consiste em efetuar transformações elementares (permutações) sobre a matriz de incidência $\mathrm{A}$ até obter outra diagonalizada por blocos, isto é, todas suas submatrizes são nulas, exceto as submatrizes diagonais. A justificativa de se procurar atingir a forma diagonalizada por blocos baseia-se num princípio bastante claro. Como as submatrizes não nulas representam incidência de máquinas em peças e estas deverão estar agrupadas, bem como o movimento intercelular/interdepartamental de peças deve ser o menor possível (de preferência inexistente), fica claro que a correspondente 
PRODUÇÃO

matriz de incidência deverá apresentar

submatrizes não nulas concentradas na forma diagonal por blocos.

No final, as submatrizes diagonais, obtidas pela transformação, apontam as células de manufatura que definem os seus grupos de máquinas e as famílias de peças correspondentes.

Seguem os passos do algoritmo "ROC estendido".

$$
\text { repita ("m" vezes) }
$$

da última coluna para a primeira

faça

localize as linhas (máquinas) com entrada; mova as linhas com entradas para a cabeça de linhas, mantendo uma prévia ordem de entrada (ordem anterior à nova iteração). As linhas sem entrada vêm a seguir mantendo, também, a prévia ordem de entrada (ordem anterior à nova iteração).

\section{$\underline{\text { fim faça }}$}

da última linha para a primeira

$$
\text { faça }
$$

localize as colunas (componentes ou peças) com entrada; mova as colunas com entradas para a cabeça da lista de colunas, mantendo a prévia ordem das entradas (ordem anterior à nova iteração). As colunas sem entrada vêm a seguir mantendo, também, a prévia ordem de entrada (ordem anterior à nova iteração).

$\underline{\text { fim faça }}$

até (não mais alterar a matriz ou parar a iteração).

É mister observar que nem sempre se consegue obter, com o simples uso do algoritmo acima, uma nova matriz, equivalente a $\mathrm{A}$, na forma totalmente diagonalizada por blocos. Isto ocorre quando é inevitável, com base nos planos de processos preexistentes, a movimentação interdepartamental de peças.
Estas são denominadas peças excepcionais; as correspondentes entradas na matriz de incidência, após o tratamento do algoritmo ROC, situam-se fora das submatrizes bloco-diagonais e são, portanto, facilmente identificáveis.

Se ocorrerem peças excepcionais, resta, contudo, a possibilidade de eliminação dessa condição, através de várias estratégias como, por exemplo, reelaboração de sua folha de processo de forma adequada, modificação de seu projeto de forma a contemplar uma folha de processo conveniente, remanejamento de máquinas entre grupos principais, mudança de método de análise de grupo, subcontratação da peça etc.

c) Análise de Linha

Analisa o fluxo de materiais em cada célula formada a fim de obter o melhor arranjo para o "layout" celular. Através dos resultados obtidos nas análises anteriores, o objetivo passa a ser o de encontrar o arranjo físico das máquinas dentro de cada célula, o mais próximo do arranjo em linha.

\section{d) Análise do Ferramental}

Através da análise da matriz de incidência, obtêm-se informações sobre quais peças serão processadas em cada máquina dentro da família de ferramentas e a seqüência ótima de carregamento. O objetivo, nesse estágio, é pesquisar as peças processadas em cada máquina do grupo e determinar a melhor seqüência de carga, para minimizar os tempos de preparação das máquinas.

\section{O "software" GROUPTEC}

O "software" GROUPTEC foi desenvolvido na linguagem DELPHI 2.0 para ser utilizado em plataforma Windows. A escolha da linguagem de 
desenvolvimento Delphi decorreu da necessidade de trabalhar em um ambiente visual e multitarefa, onde os métodos de compartilhamento ou troca de dados pudessem ser executados, além dos recursos de conversão de dados para diversos formatos padrões já existentes.

É aplicado para a reorganização do setor produtivo em indústrias manufatureiras, de maneira a torná-las mais eficientes. Oferece características de suportar as informações necessárias à implantação de TG através da AFP para qualquer empresa manufatureira do setor metalúrgico. Para isso, o mesmo possui uma base de dados capaz de armazenar informações pertinentes a todos os elementos envolvidos no processo de produção como um todo.

A Figura 4 mostra a tela de abertura do "software" GROUPTEC; a Figura 5 exibe o seu fluxograma, o qual descreve todas as etapas para o cadastramento dos dados relativos à produção e às análises que constituem a AFP.

\section{Estudo de Caso}

Escolheu-se uma empresa para a realização de um estudo de caso, visando à validação do "software" como ferramenta para a realização de análise do fluxo da produção, contemplando as seguintes características:

- Possuir a variedade de produtos e volume de produção médios;

- Estar dentro da instância (tamanho) do problema em TG indicado, conforme Tabela 1;

- Possuir um sistema de produção em linha de transferência ou "layout" funcional, o que possibilita a aplicação da AFP para transformá-lo em um sistema de produção celular otimizado, conforme técnica descrita em Burbidge (1971).

Baseado nos dados a serem colhidos e no tamanho do problema de tecnologia de grupo a ser analisado, foram contatadas quatro empresas nos estados de Minas Gerais e Paraná.

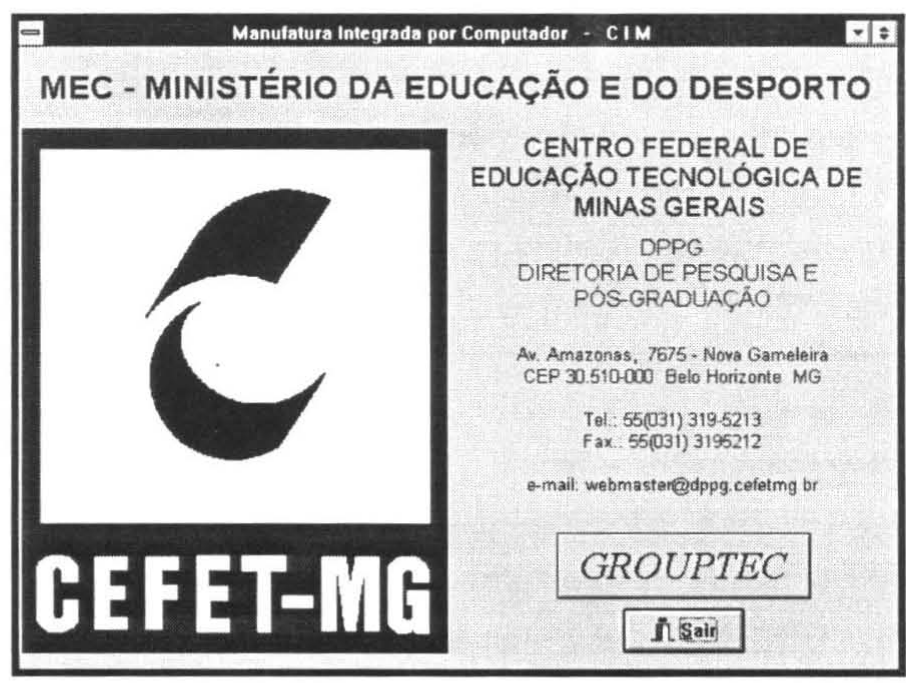

Figura 4 - Tela de Abertura do Sistema. 


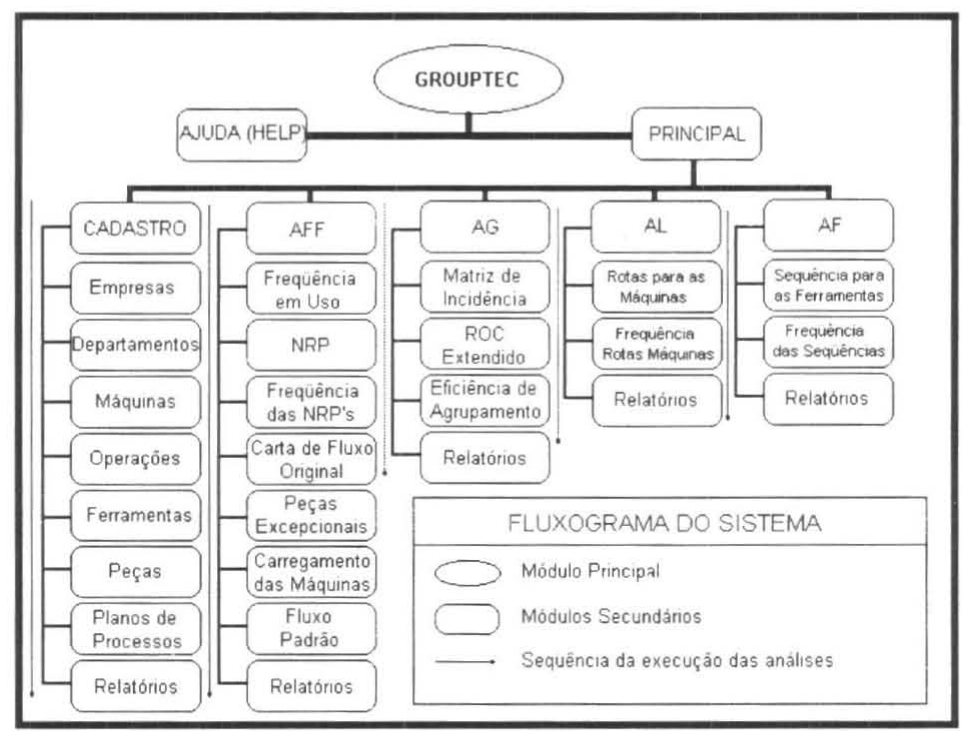

Figura 5 - Fluxograma do Sistema.

Uma das empresas Paranaenses contatadas revelou-se, afinal, a mais disposta a cooperar fornecendo os subsídios e foi, portanto, a escolhida. Iniciaram-se então os trabalhos de coleta de dados.

A coleta de dados foi demorada devido ao fato da empresa não possuir catalogados, na época, todos os dados e procedimentos relativos à produção. Após visitas às instalações da fábrica e análise dos documentos fornecidos, pôde-se concluir essa etapa, a qual demandou um tempo de seis semanas. Foram utilizadas sete (7) tipos distintos de planilhas com informações pertinentes aos processos, materiais e máquinas, totalizando aproximadamente 250 planilhas para compor todo o acervo de informações.

Os dados cadastrados poderão ser apreciados através dos relatórios emitidos pelo sistema. São eles: os relatórios de empresas, de departamentos por empresa, de máquinas, de peças, de operações, de ferramentas, de planos de processos.

\subsection{Análise do Fluxo da Fábrica}

Após o cadastramento de todos os dados deu-se início às quatro análises conhecidas que compõem a AFP.

Primeiramente detectou-se, através da análise do fluxo da fábrica selecionada, que algumas máquinas constituíam células tecnológicas, ou seja, apresentavam uma divisão natural e intrínseca ao processo por serem necessárias a quase todas as peças a serem produzidas, como por exemplo a máquina 1 .

O Gráfico 1 exibe a freqüência de utilização das máquinas. O eixo horizontal representa cada máquina utilizada na indústria e o eixo vertical a sua freqüência de utilização. Pode-se verificar que algumas máquinas possuíam freqüências altas enquanto que outras, freqüências muito baixas.

Foram identificadas, também, máquinasgargalo para o processo, ou seja, que apresentam alta freqüência de uso e problemas com tempo de carregamento. Para cada uma realizaram-se 
estudos visando à elucidação das prováveis causas dos gargalos, bem como foram, desde então, tomadas decisões buscando soluções viáveis, segundo estratégia arbitrada pela gerência. As máquinas gargalo, identificadas pelo GROUPTEC utilizando as medidas de freqüência e tempo de carregamento, foram: 3, 6, 9, 11, 13, $19,22,23,28,35$ e 36 . mesmo carregamento do "layout" funcional, agora em um "layout" celular. Somente as máquinas que aparecerem em mais de um departamento devem ser testadas, de vez que se a máquina que aparece em apenas um departamento já suportava o carregamento para o "layout" antigo, irá suportar, por consequência, o carregamento no novo "layout".

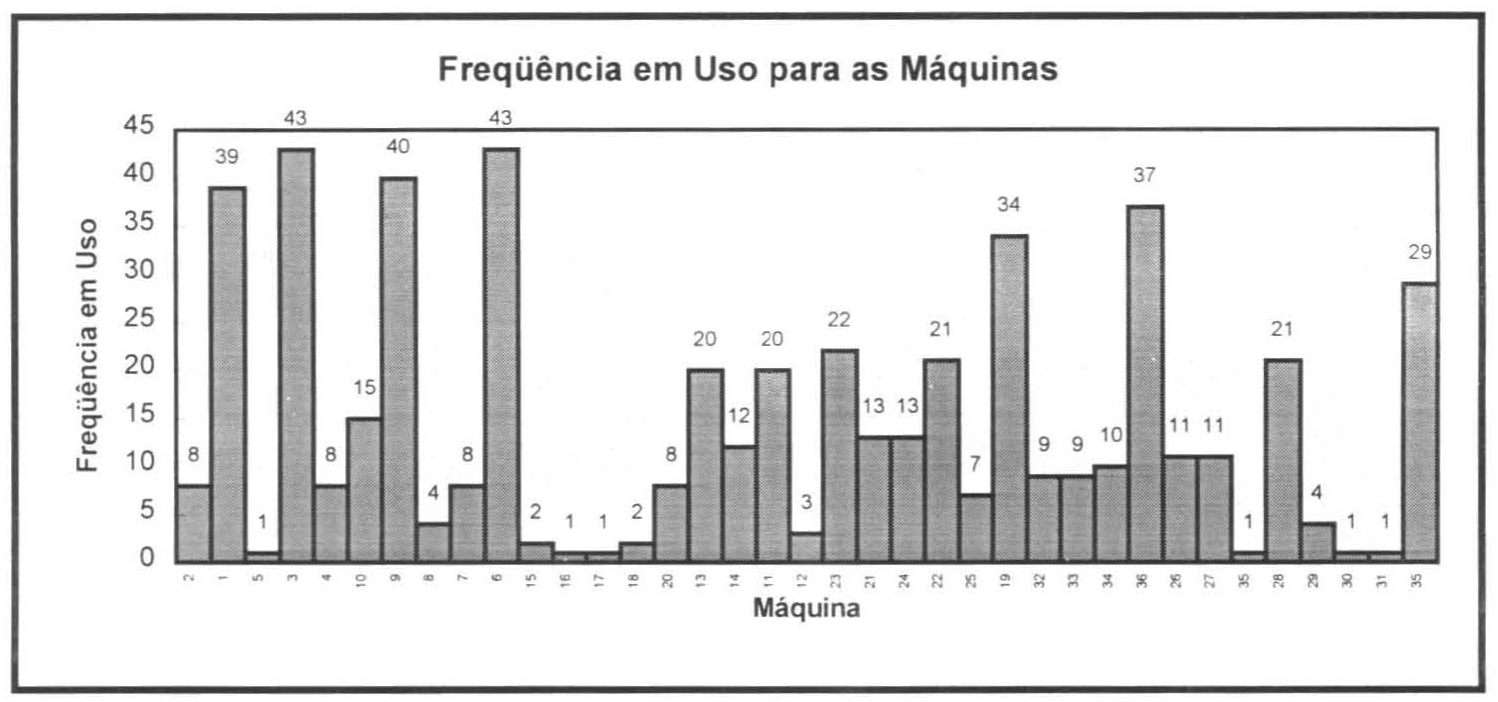

Gráfico 1 - Gráfico Frequêencia de Utilização das Máquinas.

O Gráfico 2 mostra as rotas de processos existentes no chão-de-fábrica, encontradas. A freqüência de utilização das rotas de processos para as peças foi levantada, onde se constatou que algumas eram muito baixas ou muito altas em relação à média global. Através desta informação, pôde-se visualizar as peças que constituíam exceções ao fluxo normal, ou seja, peças excepcionais. A escolha do critério para eliminação das peças excepcionais passou pelo crivo do estudo de caso, analisando-se individualmente cada peça e os processos envolvidos. Os critérios alternativos para eliminação das exceções são aqueles citados atrás no Capítulo 4.

Finalmente, realizou-se o teste do carregamento das máquinas, as quais devem suportar o
Caso haja máquina não suportando o carregamento em "layout" celular, a mesma deverá ser estudada para medida corretiva. Neste caso, a máquina poderá sofrer alteração de "setup", ou ser duplicada para atender à demanda e não se constituir num gargalo de produção. Fica estabelecido, então, o sistema de fluxo padrão entre os departamentos.

\subsection{Análise de grupo}

$\mathrm{Na}$ análise de grupo, tratou-se a matriz de incidência, instituída através dos dados previamente cadastrados nos planos de processos, pelo algoritmo ROC estendido que, reorganizou a matriz através de permutações de linhas e colu- 


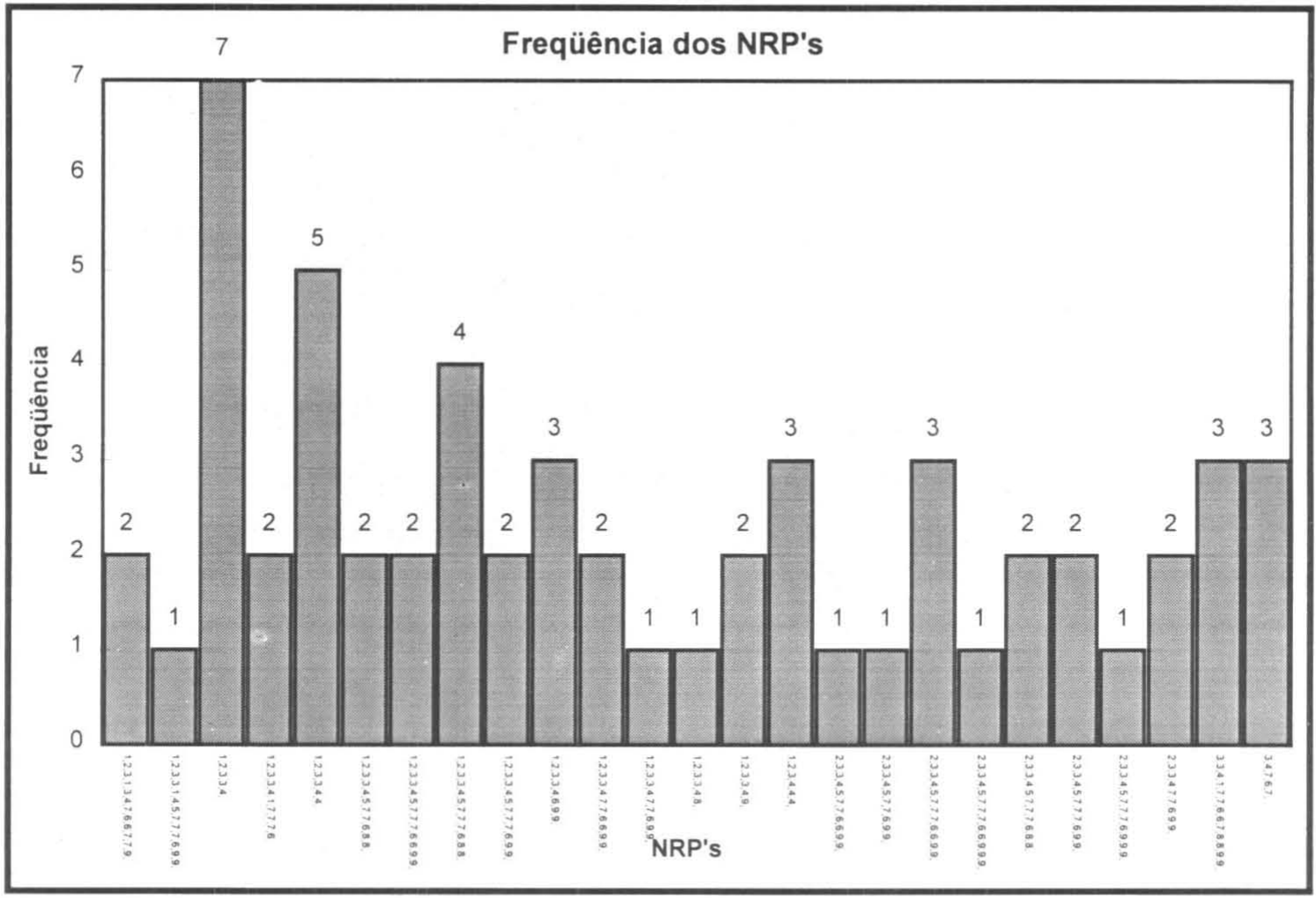

Gráfico 2 - Gráfico da Frequêencia dos NRP.

nas, para apontar as células tecnológicas. $\mathrm{Na}$

Figura 6, está representada a matriz de incidência original gerada pelo sistema GROUPTEC, a partir dos planos de processos das cinqüenta e oito (58) peças processadas pelas trinta e seis (36) máquinas da empresa..

Após submeter a matriz da Figura 6 ao ROC estendido, a eficiência de agrupamento alcançada foi de aproximadamente $39,4 \%$, considerada muito baixa. Isto se deve ao fato de os elementos não nulos da matriz de incidência estarem dispersos, em decorrência das características intrínsecas aos processos envolvidos e da infraestrutura da indústria. O processo de transformação da matriz em questão não convergiu, de pronto, para uma solução ótima devido ao grande número de elementos excepcionais existentes, nesse tratamento inicial, sem modificações dos planos de processos.
$\mathrm{Na}$ busca de uma solução ótima, fizeram-se algumas modificações relativas aos planos de processos (PP) e quanto ao número de máquinas do mesmo tipo existentes na indústria. Após tais alterações, alcançou-se uma eficiência de agrupamento de $98,9 \%$, o que é um sucesso. As alterações nos PP constituíram-se na alteração de rotas de processos, alteração do "setup" de algumas máquinas, inclusão e exclusão de máquinas, troca de máquina para realizar a mesma operação desafogando uma máquina gargalo e utilizando outra com baixa freqüência em uso.

Assim, houve a alteração de alguns planos de processos para algumas peças, com a inclusão de algumas máquinas que necessitavam duplicação. As máquinas duplicadas foram as seguintes: cortadeira redonda chapa fina até $2 \mathrm{~mm}$, arrebitadora, furadeira semi-automática e seladora. Essas alterações explicam a presença de 
numerações novas, nos gráficos e tabelas que seguem, correspondentes às novas máquinas.

Procurando obter uma eficiência maior, os planos de processos foram, afinal, reformulados para quase todas as peças.

Note-se, portanto, que o processo global das várias etapas de análise visando uma solução otimizada tem, em geral, um procedimento recursivo. uma célula e retornar à mesma para que o ciclo de manufatura seja complementado.

Com a aplicação dos resultados da análise, custos de movimentações intercelulares foram reduzidos ao mínimo. A eficiência de agrupamento alcançada de $98,9 \%$ pode ser considerada excelente. Constatou-se, também, que algumas máquinas utilizadas não eram necessárias e foram retiradas dos planos de processos.

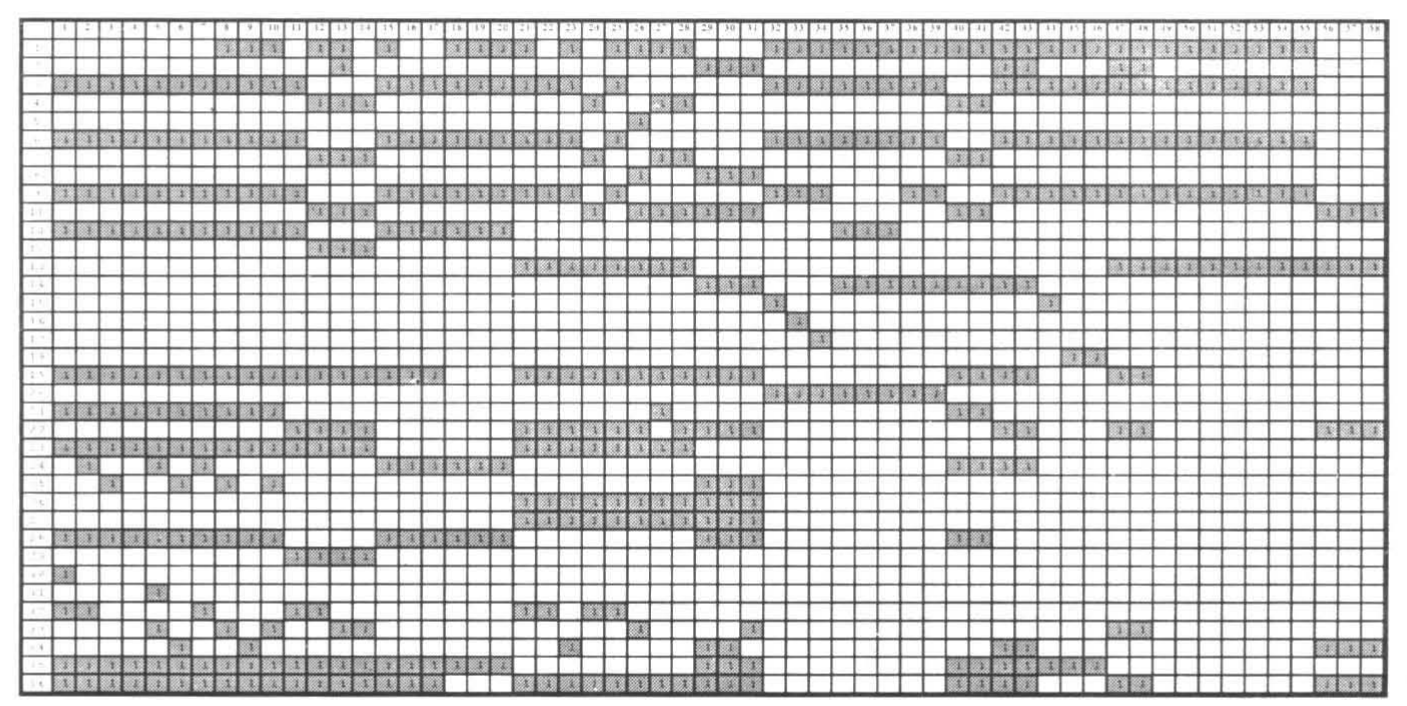

Figura 6 - Matriz de Incidência Original - Empresa Paranaense.

Veja a seguir, através da Figura 7, os resultados alcançados e a nova matriz de incidência, após as alterações já descritas.

O resultado obtido revela 3 (três) células básicas de manufatura e 5 (cinco) elementos excepcionais. As peças 13,19,44,45 e 46 não apresentaram um fluxo comum à maioria, sendo assim consideradas peças excepcionais. O número de movimentos intercelulares para as peças excepcionais foi de 2 (dois), pois, elas necessitam sair de
A Tabela 2 apresenta a relação de células tecnológicas com os grupos de máquinas e famílias de peças formadas pelo sistema após a AG.

Em virtude da reformulação dos PP, obteve-se nova freqüência de utilização das máquinas que se encontra descrita no Gráfico 3. Observou-se que a nova distribuição das operações de manufatura ficou mais homogênea, evitando que máquinas antes com boa utilização tivessem a redução na carga de trabalho e permitindo que máquinas 
PRODUÇÃO

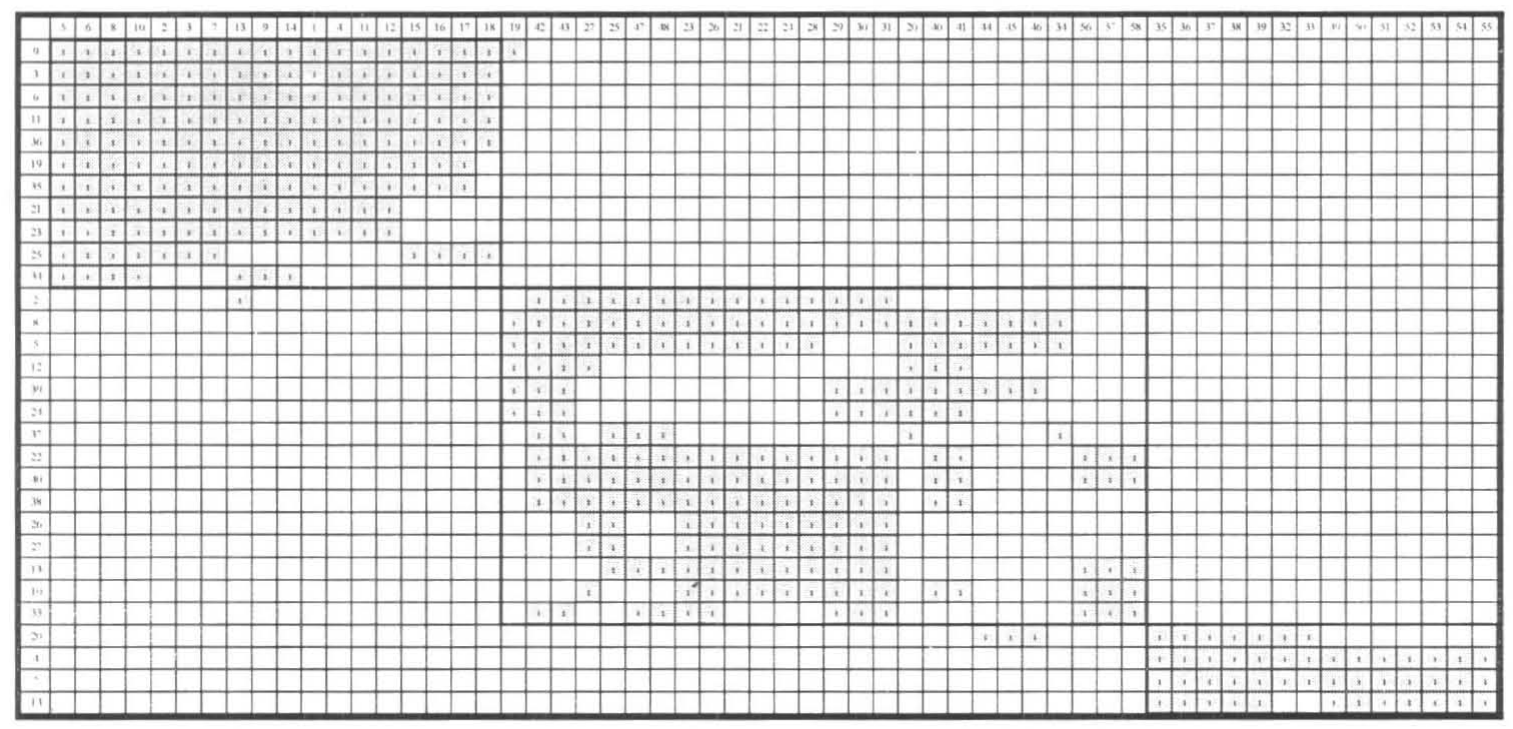

Figura 7 - Matriz de Incidência Reorganizada após 1 (uma) iteração.

com pouca utilização pudessem ser melhor aproveitadas. Algumas máquinas foram então duplicadas e outras retiradas dos processos produtivos, conforme dito anteriormente. Para tanto, verificou-se a necessidade da realização dos testes de carregamento para as máquinas do mesmo tipo, que aparecem em mais de uma célula, para o levantamento dos custos associados e dos tempos em operação. $\mathrm{O}$ teste de carregamento serve para examinar se a máquina suportará a nova carga de trabalho a que se submeterá; é feito utilizando-se os tempos das operações, os tempos de ajuste de "setup", os tempos de troca de ferramentas e os custos associados a esses tempos. Tais medidas foram tomadas para a confirmação da análise de grupo. Após realizadas, demonstraram que as máquinas não estavam submetidas a sobrecarga significativa. A máquina 1 (um) por ser necessá-

\begin{tabular}{|c|c|c|}
\hline $\begin{array}{c}\text { Célula Tecnologica } \\
\text { (ct) }\end{array}$ & \multicolumn{1}{|c|}{$\begin{array}{c}\text { Familia de Peças } \\
(\mathrm{fp})\end{array}$} & $\begin{array}{c}\text { Grupo de Máquinas } \\
(\mathrm{gm})\end{array}$ \\
\hline 1 & $1,2,3,4,5,6,7,9,10,11,12,13,14,15,16,17,18$ & $3,6,9,11,19,21,23,25,34,35,36$ \\
\hline 2 & $\begin{array}{l}19,20,21,22,23,24,25,26,27,28,29,30,31,34,40,41, \\
42,43,44,45,46,56,57,58\end{array}$ & $2,5,8,10,12,13,22,24,26,27,33,38,39,40$ \\
& $32,33,35,36,37,38,39,50,51,52,53,54,55$ & $4,7,14,20$ \\
\hline 3 & Tabela 2 - Lista das Células Tecnologicas Formadas após a AG. \\
\hline
\end{tabular}


ria a quase todas as peças e possuir capacidade de produção para a demanda da fábrica constitui-se, portanto, uma célula tecnológica.

Pode-se observar, através do Gráfico 3, que as máquinas, em geral, possuem agora freqüência de utilização inferior ao teto preestabelecido, valor este fixado em 20 (vinte). Apenas duas máquinas apresentaram freqüência de utilização superior ao teto, mas não representaram gargalo por razões já explanadas. São elas as máquinas 1 (Forno a diesel) e 8 (Guilhotina grande acima de $4 \mathrm{~mm}$ ). empregada face à necessidade de produção e não a capacidade da máquina de atender uma ou outra operação. Essas máquinas receberam tratamento específico, caso a caso, no que diz respeito aos processos, e localizadas estrategicamente em uma célula tecnológica. As demais máquinas foram estudadas e agrupadas via análise do fluxo de fábrica e análise de grupo. Em cada célula foram realizados estudos para minimizar tempos de operação através da análise de linha, e, com isso, estabelecida uma seqüência

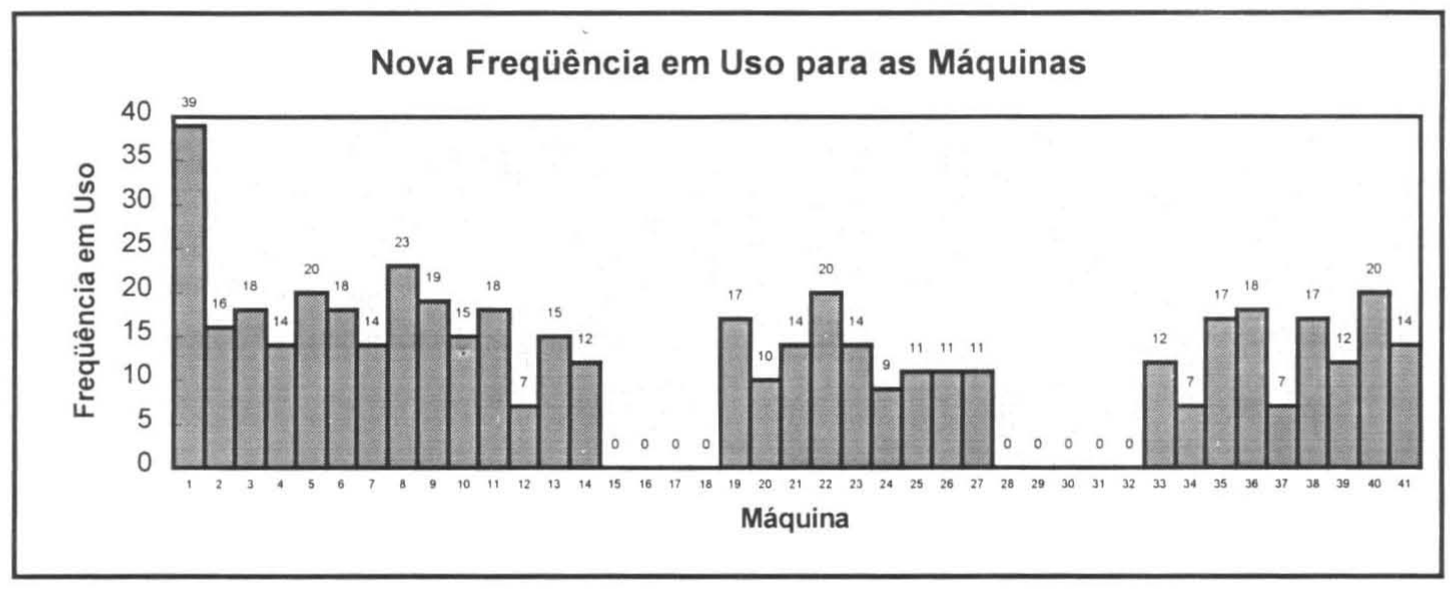

Gráfico 3 - Nova Freqüência de Utilização para as Máquinas.

\subsection{Resultados Obtidos Após AFP e Decisões Tomadas}

Inicialmente, os resultados obtidos evidenciaram a ineficácia do sistema produtivo praticado pela fábrica, antes da análise. O sistema anterior adotado, conforme planta existente, caracterizado como um sistema em "layout" funcional, não se apresentava como o melhor modelo de produção para o seu caso. Numa primeira análise, por inspeção visual, foi detectado o emprego de máquinas tecnologicamente essenciais a quase todas as peças, resultando na necessidade de células tecnológicas, onde o importante é a tecnologia ótima obedecendo às rotas de processo mais utilizadas. Após as três análises citadas, realizou-se a análise do ferramental, com o objetivo de encontrar, em seguida, as seqüências ótimas de utilização das ferramentas.

O cálculo da eficiência do processo produtivo antes e depois da análise não foi realizado face à necessidade de restruturação fabril, cuja operacionalização implicaria em uma interrupção da produção para remanejamento das máquinas, compra de novas máquinas, treinamento de pessoal e restruturação dos procedimentos para os setores de projeto e produção. Levantou-se, 
porém, a estimativa de que o rendimento da produção se elevaria para cerca de $30 \%$ após a migração para o novo sistema, o que significa um avanço considerável. Elaborou-se tal estimativa com base num estudo rápido de análise de custos. A empresa mostrou-se motivada em implementar as medidas recomendadas pelo estudo, caso uma metodologia de migração para o novo sistema fosse apresentada, sem a interrupção da produção e com prejuízos mínimos.

\section{Observações Finais e Conclusões}

A análise do fluxo da produção, aplicada ao caso da indústria Paranaense, evidenciou que os processos produtivos antes utilizados minoravam a produtividade e a flexibilidade da produção como um todo. Além do mais, os processos adotados majoravam os custos de produção. Uma visão menos nítida, no início da análise, do processo como um todo e de como otimizá-lo tornou-se clara, ao final, e procedimentos de tomadas de decisões puderam ser planejados para a otimização do 'sistema produtivo.

Em conseqüência. o tratamento elaborado para a empresa enfocada apontou as seguintes sugestões: alteração do modelo produtivo de "layout" funcional para "layout" celular, formação de células tecnológicas baseadas em planos de processos e em características tecnológicas, restruturação de todos os procedimentos para os setores de projeto e produção, treinamento de todos os funcionários envolvidos com o sistema produtivo, elaboração de uma estratégia de migração para o novo sistema sem prejuízo da produção, compra de novas máquinas para duplicação das que são consideradas gargalo de produção, informatização e integração entre os setores de projeto e produção e a utilização de um sistema CAD.
Em conclusão, o "software" desenvolvido revelou-se uma ferramenta capaz de propor soluções para reorganizar o sistema produtivo em indústrias de médio e pequeno porte do ramo metalúrgico, através da análise do fluxo da produção, metodologia essa fundamental para a aplicação da tecnologia de grupo.

Uma análise de casos mais complexos poderá doravante ser feita de maneira rápida e segura. Além disso, o acesso à tecnologia está assegurado a pequenas e médias empresas, tendo como característica principal não necessitar de elevados investimentos para a obtenção de melhores resultados quanto à produtividade, $\mathrm{e}, \mathrm{com}$ isso, concorrer com as grandes empresas em melhores condições. Com os códigos gerados é possível integrar outros "softwares" de projeto e auxílio à manufatura.

Em futuros trabalhos, pretende-se implementar um sistema multi-empresa. Outra meta importante seria a realização da análise de tecnologia de grupo utilizando modelos que consideram características de forma geométrica e planos de processos simultaneamente. Akturk e Balkose (1996) sugerem um modelo para TG que utiliza as duas características mencionadas. Outra característica importante seria a gravação e recuperação das informações via disquetes, onde o próprio usuário poderia armazenar e selecionar os dados de trabalho pretendidos por ele. Na versão atual, o usuário sempre tem disponíveis as últimas informações trabalhadas. Caso modifique os dados ele perderá as informações antigas e ficará somente com as mais recentes. Entretanto, o GROUPTEC disponibiliza um histórico das informações através dos relatórios antigos emitidos pelo sistema, os quais podem ser gravados em disquete. Uma solução menos comum, mas eficiente, é a de salvar (gravar) o subdiretório de dados em disquetes e no 
futuro copiar os dados de volta para o subdiretório, a fim de revê-los ou refazer as análises para aquela empresa.

Cumpre, ainda, observar que o conhecimento pode ser embutido no sistema de maneira que $o$ próprio "software" julgue e decida numa escala cada vez maior, retirando o ônus de decisão por parte do usuário, tornando-se um sistema especialista. Esta medida visa reduzir enganos durante a fase de implantação da tecnologia de grupo.

Demais, é possível embutir no sistema outras técnicas de classificação e codificação diferentes da utilizada e, até mesmo, a possibilidade de escolha por parte do usuário. É possível, ainda, incluir o modelo de formação de células utilizando rotas de processos alternativas (Adil et al. 1996), para analisar cada uma delas e escolher a melhor rota de processo.

É mister enfatizar que a TG é uma excelente ferramenta de suporte à tomada de decisões no processo produtivo que, como a maioria das ferramentas, não dispensa a experiência e competência do usuário tanto no que afeta ao "know-how" do processo de manufatura quanto à utilização da técnica de TG. Quanto maior o grau de competência, maior será o proveito que se fará da ferramenta. Finalmente, é mister ponderar que a análise permitida pela TG faz parte do processo global de gerenciamento da empresa, o qual envolve problemas outros que escapam ao escopo de tratamento ofertado pela TG.

\section{Agradecimentos}

Os autores agradecem ao $\mathrm{CNPq}$ (Proc. 30.0407/84-cc) e FINEP (Conv. 77.97.0779.00) pelo suporte à pesquisa.
9. Bibliografia

ADIL, G. K., RAJAMANI, D., STRONG, D. Cell formation considering alternate routeings. Int. J. Prod. Res., v. 34, n. 5, p.1361-1380, 1996.

AKTURK, M. S., BALKOSE, H. O. Partmachine grouping using a multi-objective cluster analysis. Int. J. Prod. Res., v. 34, n. 8, p.22992315, 1996.

BOCTOR, F. F. The minimum-cost, machinepart cell formation problem. Int. J. Prod. Res., v. 34, n. 4, p.1045-1063, 1996.

BURBIDGE, J. L. Production flow analysis. The Production Engineer, p.139-152, april-may, 1971.

CHENG, C. H., MADAN, M. S., MOTWANI, J.. Designing cellular manufacturing systems by a truncated tree search. Int. J. Prod. Res., v. 34, n. 2, p.349-361, 1996.

CHOI, M. J. An exploratory study of contingency variables that affect the conversion to cellular manufacturing systems. Int. J. Prod. Res., v. 34, n. 6, p.1475-1496, 1996.

CHOOBINEH, F. A framework for the design of cellular manufacturing systems. Int. J. Prod. Res., v. 26, n. 7, p.1161-1172, 1988.

CRAMA, Y., OOSTEN, M. Models for machine-part grouping in celular manufacturing. Int. J. Prod. Res., v. 34, n. 6, p.1693-1713, 1996.

GALLACHER, C. C., KNIGHT, W. A. Group technology production methods in manufacturing. John Willey \& Sons, 1986, 190p. 
PRODUÇÃO

GODOY, C. A.. Tecnologia de Grupo: Um

ambiente Computacional. Curitiba, Paraná. 1992.

GUPTA, Y., GUPTA, M., KUMAR, A., SUNDARAM, C.. A genetic algorithm-based approach to cell composition and layout design problems. Int. J. Prod. Res., v. 34, n. 2, p.447482, 1996.

KUSIAK, A. Intelligent manufacturing systems. Series in Industrial and Systems Engineering. USA: Prentice Hall International, 1990, 441p.

LACERDA, J. M. de. CIM-MM Explorando as conexões da multimídia com a manufatura integrada por computador. Rev. Byte, São Paulo, n.5, p.82-85, 1993.

MAC AULEY, J Machine grouping for an efficient production. The Production Engineer, p. 53-57, february, 1972.

MITROFANOV, S. P... Scientific principles of group technology. English Translation. National Library for Science and Technology, Washington, D.C., 1966.

RADOS, G. J. V. Tecnologia de grupo uma filosofia de trabalho. Máquinas e metais, p.35-43, junho, 1986.

ROSEL, J. M. A. Fabricación integrada por ordenador (CIM). 1.ed. Barcelona: Marcombo S.A., 1992, 223p.

SIMON, H. A. As ciências do artificial. Trad. Luís Moniz Pereira. 2.ed. rev. aum.; Coimbra: Arménio Amado, Editor Sucessor, 1981, 351p.
SOUZA, J. U.F. de. Tecnologia de grupo: algoritmos e ferramenta gráfica. Dissertação de Mestrado, CPGEI/CEFET-PR, 1991, 203p. 